\title{
RESPONSE TO LOTHERINGTON-WOLOSZYN
}

\section{Anne Hetherington}

Heather Lotherington-Woloszyn has provided a welcome forum for further discussion of the elusive nature of text comprehensibility. For the most part, I would agree with the points she has made but feel that some of my earlier remarks have been misinterpreted.

In my own ESL teaching, I have used a wide variety of reading materials including newspaper, magazine and textbook articles as well as published ESL texts and L1 graded materials. However, I have been disappointed to find that there is often a wide range of difficulty within a set of graded reading passages supposedly written at the same level; some are too easy, others too difficult and others suitably challenging. In my original article I explored the criteria used in grading many of these materials and discussed a number of other criteria which I have found important in assessing suitability of reading materials.

I began the article with a discussion of the simplification formulae used by $\mathrm{L} 1$ and $\mathrm{L} 2$ publishers as both types of materials are used in many ESL classrooms. Although there is some overlapping of criteria between the two, it was not my intention to imply that the formulae used for L1 materials are extensively used by publishers of $\mathbf{L} 2$ texts. My purpose in analyzing these formulae was to "demystify" them and to alert teachers to their limitations. Such labels as "grade level 3:2" seem to provide teachers with a short-cut for assessing text difficulty. In fact, however, such ratings provide only a rough estimate of the linguistic difficuly of a text, only one of a number of factors to be considered when assessing text suitability for particular learners.

Lotherington-Woloszyn mentions her own research into criteria used in the production of simplified texts for ESL learners, studies which indicate that publishers consider many variables other than linguistic features. This is a welcome addition to the field and I hope she will publish more details of her findings. I found that while much had been written on L1 simplification criteria, relatively little had been written on ESL criteria other than the brief descriptions given on book jackets and in catalogues.

The body of my original article consisted of a discussion of reading as an interactive process and showed how and why variables such as the type of information in a text and students' background knowledge, as well as discourse and rhetorical features must be considered when assessing text comprehensibility for a particular group of learners. It was not my intention in so doing to advocate that particular difficult features of the language, text organization or information content be systematically deleted from texts. I would wholeheartedly agree with Lotherington- 
Woloszyn that the ESL teacher's intuitive simplification of the text is preferable to either content abridgement or structurally defined linguistic simplification. It has been my experience as a teacher trainer, however, that the beginning ESL teacher, or the ESL teacher who is adapting from a structural approach to a more communicative orientation may not have the experience necessary to make intuitive simplifications, or may not have the confidence to do so. It is not enough to tell these teachers to rely on their intuition. Some broad guidelines to possible areas of difficulty are necessary; it was the need for such guidelines that prompted me to write my original article.

One might conclude from my discussion, as Lotherington-Woloszyn has done, that I advocate a teacher-centred approach to materials selection and adaptation. This is certainly the approach discussed in the article. Like Lotherington, however, I would welcome more opportunities for student selection of materials and would encourage this in certain settings and for certain reading tasks. It is important to realize, nonetheless, that such an approach is limited. First of all, most teachers find themselves in a situation where they are required to provide most of the reading materials. This need not necessarily imply that all students are reading the same text. They may, in fact, read different articles related to a common theme but at different levels of difficulty. In ESL classes in which oral interaction, listening and writing skills are given as much time as or more time than reading, teacher selection of reading texts is often the most efficient and effective way to integrate the skills. Secondly, such an approach can only be used with fairly advanced learners. Until students can cope with newspaper and magazine articles (which often assume background knowledge and cultural awareness foreign to many L2 learners) and textbooks related to their own field of expertise, teacher selection of materials must play a major role.

I was interested in Lotherington-Woloszyn's suggestions for student simplification of texts and would be interested in hearing more about the success of this technique with students at a variety of levels. Having students underline problem areas in self-selected texts is certainly a useful procedure but I wonder how many students in our communicativelyoriented classes have the expertise to analyze these problems and identify the cause of their difficulty. In light of Lotherington-Woloszyn's remarks about the perceived versus the actual role of vocabulary in comprehensibility, I wonder how much training students would need in order to do this kind of exercise. I have no doubt that advanced students in English for Academic Purposes courses would find it interesting and very helpful, but I question its suitability for students at lower language levels or students with a less academic orientation.

In conclusion, I would agree with Lotherington-Woloszyn's suggestion 
that teachers write intuitive simplifications of difficult texts rather than deleting specific structures or features. I would also strongly agree with her suggestion that students be taught to cope with ungraded texts. Even with very low level language classes, I have always presented students with some carefully selected ungraded newspaper or magazine articles. With appropriate exercises focusing on key information and language, such texts can be used to develop essential strategies so that students can learn to read independently of a teacher and graded texts. However, I also feel strongly that experienced teachers and teacher trainers have a responsibility to give new ESL teachers guidelines for text selection and, if necessary, text adaptation. Just as we provide our ESL students with strategies for coping with difficult reading texts, we should provide teachers with strategies and guidelines for coping with the difficult job of assessing text suitability for their students.

\section{THE AUTHOR}

Anne Hetherington is a sessional lecturer in the TESL Centre at Concordia University. She has extensive experience in teaching and materials development at the primary, secondary and adult levels, including EAP and ESP. 